\title{
DEFORMATION MONITORING USING SATELLITE RADAR INTERFEROMETRY
}

\author{
M. Crosetto ${ }^{1, *}$, L. Solari $^{1}$ \\ ${ }^{1}$ Centre Tecnològic de Telecomunicacions de Catalunya (CTTC/CERCA), Geomatics Division, Av. Gauss, 7 , \\ E-08860 Castelldefels (Barcelona), Spain, mcrosetto@cttc.cat, lsolari@cttc.cat
}

KEY WORDS: SAR, DInSAR, Persistent Scatterer Interferometry, European Ground Motion Service

\begin{abstract}
:
The paper is focused on the Persistent Scatterer Interferometry (PSI) technique. First, it addresses the substantial evolution of PSI in the last twenty years. Three main factors are identified: the availability of SAR images, the development of advanced data processing techniques, and the increase of the computation capability. The paper then addresses the PSI deformation monitoring initiatives at regional and national scale. Finally, in the last section, it is described a pan European deformation monitoring service: the European Ground Motion Service (EGMS).
\end{abstract}

\section{INTRODUCTION}

This paper describes some key aspects of the Persistent Scatterer Interferometry (PSI) techniques. The PSI techniques represent an advanced class of Differential SAR interferometry (DInSAR), a technique based on interferometric pairs of SAR images to measure and monitor deformation of the natural environment, the built environment and infrastructures. For a general PSI review see Crosetto et al. (2016).

The DInSAR working principle allows the displacements of the imaged scene to be derived from just two complex Synthetic Aperture Radar (SAR) images. This principle has been widely exploited in the last 30 years, yielding significant results in the fields of seismology (Massonnet et al., 1993; Dalla Via et al., 2012), vulcanology (Massonnet et al., 1995), glaciology (Goldstein et al., 1993), landslides (Carnec et al., 1996), ground subsidence and uplift (Galloway et al., 1998), etc. Comprehensive reviews of different DInSAR applications are provided by Massonnet and Feigl (1998) and Hanssen (2001).

The PSI techniques offer advanced deformation monitoring capabilities, thanks to the use of large stacks of SAR images acquired during the monitoring period over the same area, and appropriate data processing and analysis tools to estimate the deformation components. From the first PSI algorithm, published in 2000 (Ferretti et al., 2000), the PSI techniques have undergone a continuous development.

This paper briefly describes the key aspects of the PSI development in the last two decades, see Section 2. Then, in Section 3, it describes some of the most important ongoing PSI initiatives, both at regional and national scales. Finally, in Section 4 it describes a recent and ambitious initiative: the European Ground Motion Service.

\section{PERSISTEN SCATTERER INTERFEROMETRY}

As mentioned above, in the last 20 years the PSI techniques have undergone a dramatic evolution. This is basically due to three main factors.
The first key factor is SAR data availability. This is a clear necessary condition for the development of PSI deformation monitoring. The first decade of PSI development has been mainly based on the exploitation of medium-resolution C-band data from ERS-1/2, Envisat and Radarsat. The data acquired by these satellites cover long periods of time: this is a key aspect to guarantee a long-term deformation monitoring.

A major step forward for the development of PSI techniques and their applications has been given by the very high resolution X-band data (coming from the TerraSAR-X and COSMO-SkyMed sensors). They provide advanced monitoring capabilities in terms of dense spatial sampling, a high sensitivity to small displacements and a remarkable quality improvement of the time series with respect to the C-band. An example of Xband PSI result is shown in Figure 1. The $\mathrm{X}$-band sensors started their acquisitions in 2007. They are still acquiring using several available satellites and have plans to guarantee data acquisition for at least the next decade.

A further significant improvement for PSI has been represented by the launch of the C-band sensors onboard the two Sentinel-1 satellites (the first one was launched in 2014). The Sentinel-1 constellation is developed and managed by the European Space Agency (ESA) in the framework of the Copernicus program (https://www.copernicus.eu). It improves the existing data acquisition performances, especially for what concerns the area coverage, revisiting time and data throughput, considerably increasing the deformation monitoring potential of the PSI technique. It is worth mentioning that Sentinel-1 is supported by an open-source distribution strategy (Torres et al., 2012; Showstack, 2014).

The unique characteristics of Sentinel-1 have been highlighted in several works. Just to mention some works related to ground deformation monitoring, e.g. see for landslide monitoring Barra et al. (2015), Dai et al. (2016), Béjar-Pizarro et al. (2017), and Intrieri et al. (2018); for subsidence monitoring Sowter et al. (2016), Zhou et al. (2017), Devanthéry et al. (2018) and Du et al. (2018); for the monitoring of mining activity, see $\mathrm{Ng}$ et al. (2017), Carlà et al. (2018), and Du et al. (2018b).

\footnotetext{
* Corresponding author
} 


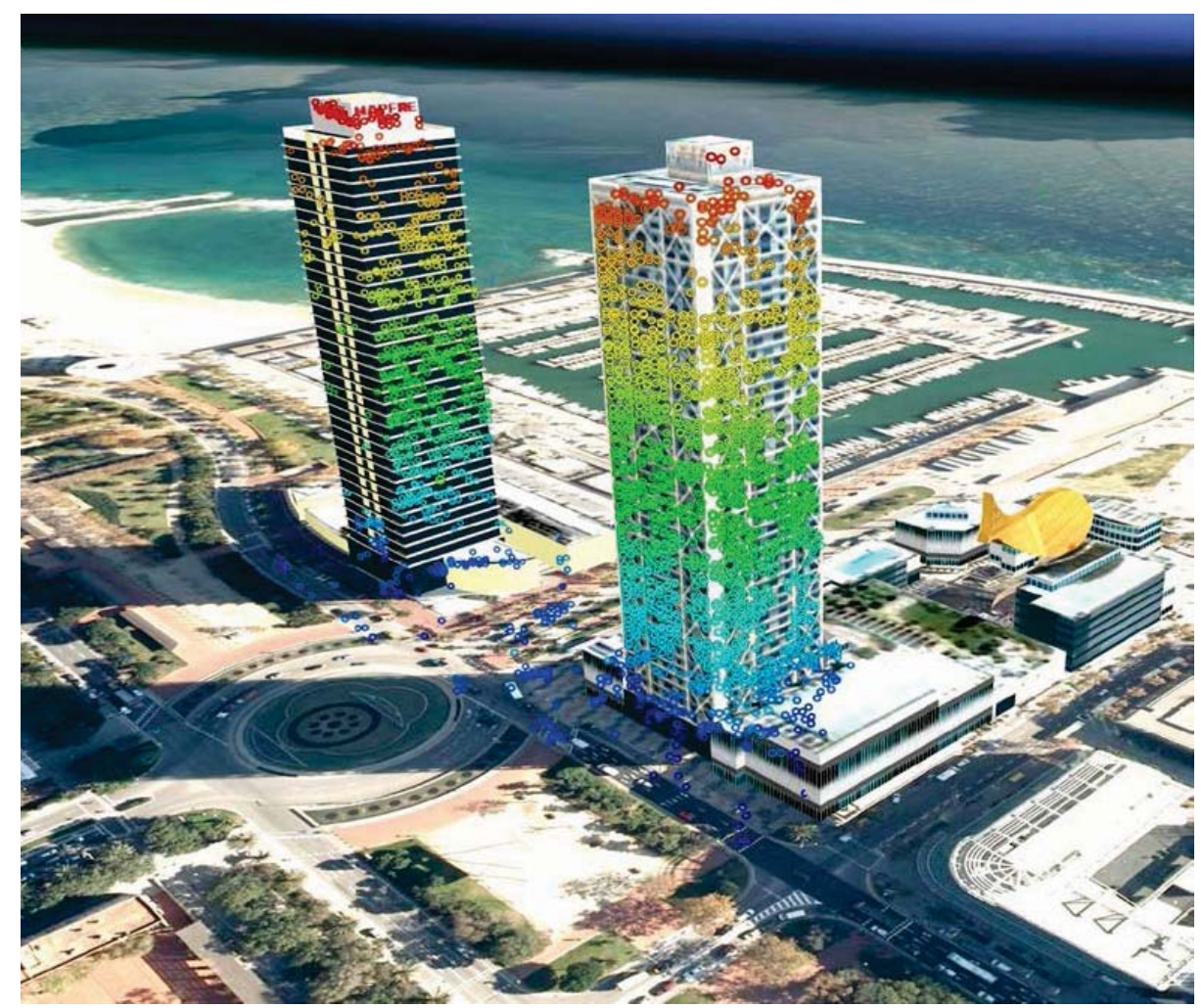

Figure 1. PSI result using TerraSAR-X data (Crosetto et al., 2010). One may appreciate the high density of measured points, which in this case are colour-coded according to the estimated height of the points with respect to a digital terrain model.

The second factor of the dramatic evolution of the PSI technique is the development of advanced data processing and analysis techniques. The first PSI technique is the Permanent Scatterers approach proposed by Ferretti et al. (2000 and 2001). These two pioneering works were then followed by several other contributions that cover all aspects of the PSI processing chain. For a general review see Crosetto et al. (2016).

The third important factor is computation capability. Special attention has been devoted to the computational aspects of the PSI processing. This is key because the data acquisition capability of the SAR sensors is overwhelmingly higher than our capacity to process and analyse the data. Several research groups and companies have worked on the exploitation of advanced computational resources, e.g. using cloud computing, distributed computing architectures, virtual machines, parallel computing, etc. The net result is that there is the capability to analyse very large stacks of radar images over wide areas, e.g. see Zinno et al., (2015) and De Luca (2017).

\section{REGIONAL AND NATIONAL INICIATIVES}

The three factors discussed in the previous section have enabled the development of regional and national PSI deformation monitoring initiatives.

The first national-scale application was based on the previous generation of C-band data: it concerned the monitory of the entire Italian territory using ERS 1 and 2, Envisat SAR images. Later COSMO-SkyMed images were used as well (Costantini et al., 2017), see Figure 2.
It is however with Sentinel-1 that industry, research centres and public authorities became aware of the real capability of satellite interferometry for ground monitoring applications and for geological risk management at large scale. Some regions and nations already have or plan to have Ground Motion Services (GMS) based on Sentinel-1 interferometric products.

In Italy, three regions have already implemented a GMS focused on the early detection of abrupt motion changes using a 12-day update of the service (Raspini et al., 2018; Solari et al., 2019). Other regions will follow in the near future, as planned in the Italian Space Economy Strategic Plan (Comerci and Vittori, 2019).

The Tuscany Region (central Italy) freely distributes continuously updated interferometric products through an open WebGIS, in which the user can visualize and download deformation maps and time series derived using both ascending and descending orbits (Figure 3). The web platform contains guidelines which explain the scientific background of the interferometric technique and give some tips for the interpretation of the results. A disclaimer for the correct exploitation of the data is present as well. The service is available at the web http://www.regione.toscana.it/-/attivita-dimonitoraggio-del-rischio-idrogeologico-del-territorio. The key interferometric products (deformation and anomalies maps) are integrated into a fully operational procedure to downscale data to different kind of users, such as municipalities and civil protection actors at regional and local scale. The deformation maps are used for landslide mapping and state of activity estimation. 


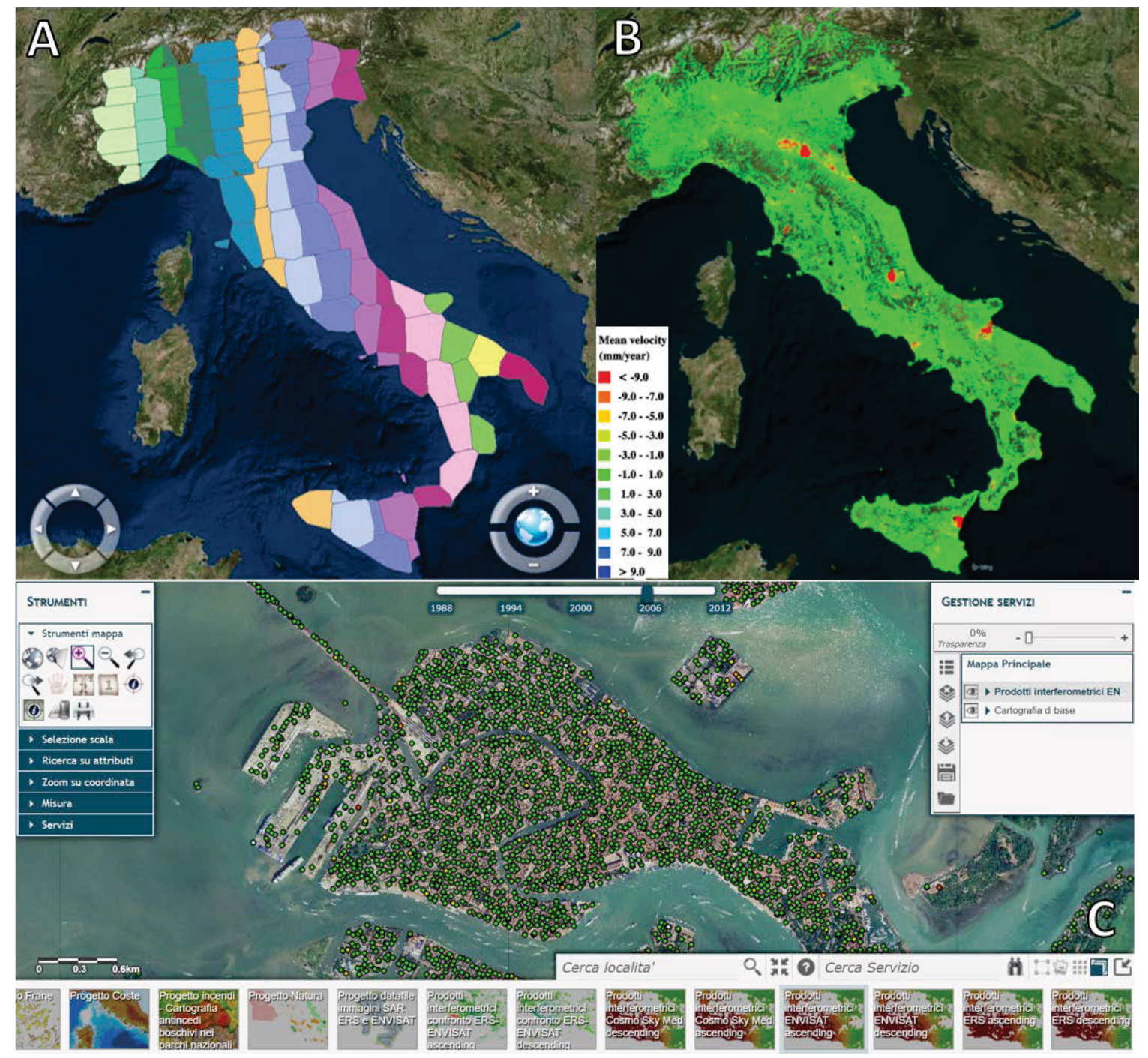

Figure 2: Italian deformation map derived from Envisat ascending data (PST-A project). A) Frames analysed; B) PS data coverage modified after Costantini et al. (2017); C) Snapshot on the city of Venice extracted from the WebGIS platform of the PST-A project.

The anomalies maps (Raspini et al., 2018) are the starting point for preliminary risk assessment at local scale. Once an area of interest is defined, an in situ ground survey involving local/regional authorities and academia takes place. The survey is aimed to define a preliminary level of risk useful for an estimation of future actions (e.g. installation of in situ instruments, etc.). The detailed description of the procedure can be found in Del Soldato et al. (2019).

Recently, the Geological Survey of Norway (NGU) published the first interferometric results covering the whole nation on an open WebGIS interface (available at https://insar.ngu.no/), see Figure 4

Denmark, France, Germany and Netherlands are currently implementing and finalizing their GMS but did not published their data yet. The Danish Agency for Data Supply and Efficiency manages and distributes the interferometric results in
Denmark. It provides interpreted and calibrated results for specific users (e.g. municipalities or infrastructure authorities). Example of this activity are:

- the city of Odense (southern Denmark - https://sdfe.dk/dataskaber-vaerdi/nyheder/nyhedsarkiv/2018/nov/nye-data-kanfortaelle-hvor-odense-synker/);

- the National Road Authority (https://sdfe.dk/data-skabervaerdi/nyheder/nyhedsarkiv/2018/dec/nye-data-kan-bidragetil-mere-effektiv-vedligeholdelse-af-veje-og-broer/).

In other nations, the feasibility of such wide area data has been assessed (Novellino et al., 2017; Vecchiotti et al., 2017).

\section{THE EUROPEAN GROUND MOTION SERVICE}

The above section shows that there is a high demand of interferometric products at European level, which has driven the development of several regional and national initiatives. 


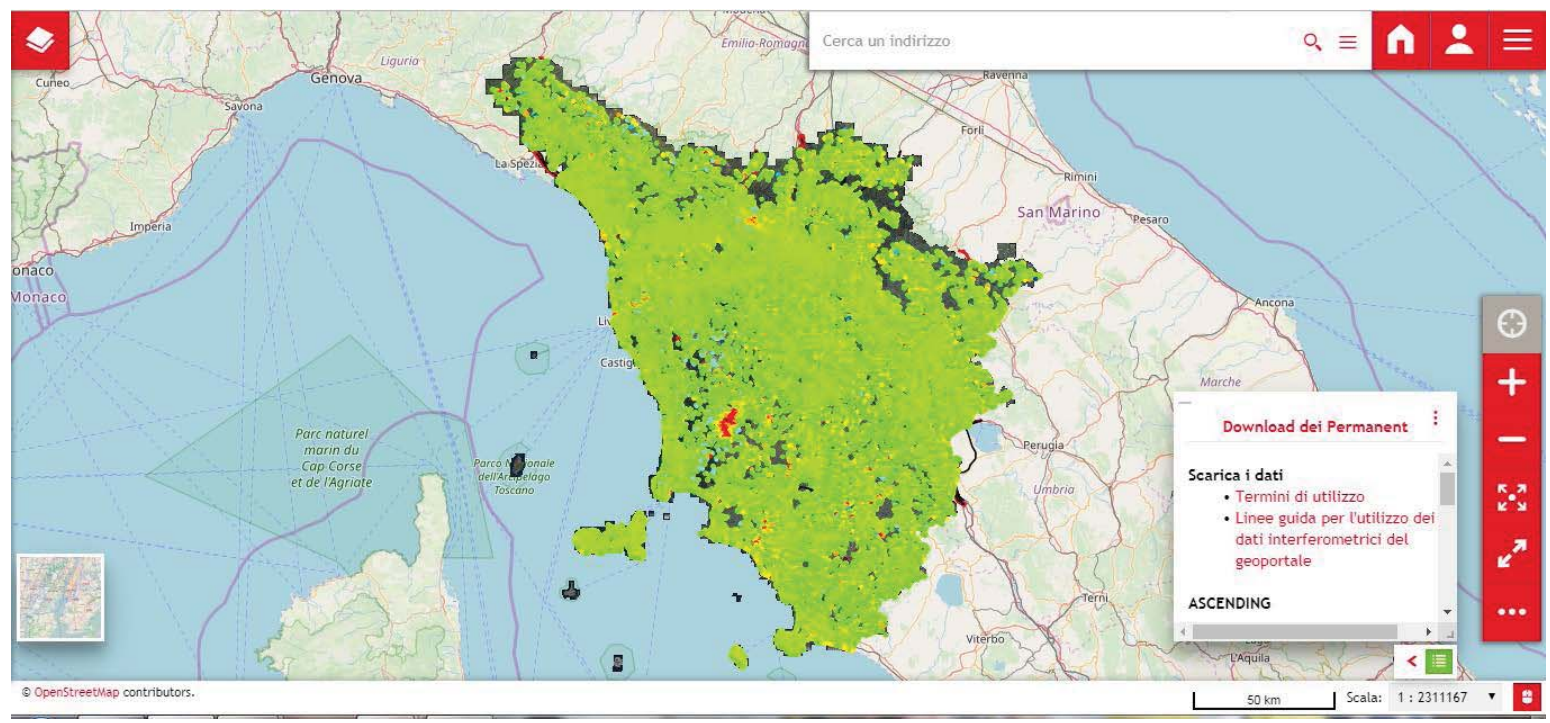

Figure 3: View of the geoportal of the Tuscany region related to the activity of monitoring of the hydrogeological risk. https://geoportale.lamma.rete.toscana.it/difesa_suolo/\#/viewer/openlayers/326.

In 2017 the Copernicus User Forum and the Copernicus Committee unanimously approved the addition of the European Ground Motion Service (EGMS) to the Copernicus Land Monitoring Service's product portfolio (land.copernicus.eu). The EGMS is to be implemented under the responsibility of the European Environment Agency (www.eea.europa.eu).

The technical specifications of the EGMS are currently under definition. However, the main characteristics of the service are already documented. In fact, the basic concepts were defined by the so-called EGMS Task Force. They are contained in the EGMS White Paper, which contains the definition of the service and outlines the EGMS portfolio, EGMS Task Force (2017).

In the following, we highlight some of the most important aspects of the White Paper.

- The Service aims to provide consistent, regular, standardized, harmonized and reliable information regarding natural and anthropogenic ground motion phenomena over Europe.

- The ground motion will be derived from time series analyses of Copernicus Sentinel-1 data, using Persistent Scatterers (PS) and Distributed Scatterers (DS). Both ascending and descending data will be used.

- The EGMS portfolio is composed of three levels:

- Level 2a, which includes a basic deformation map with measurements along the radar Line Of Sight (LOS); the product will be delivered for individual and consistent frames of image stacks.

- Level 2b, PSI deformation map integrated into a reference Global Navigation Satellite System (GNSS) network; GNSS network measurements will be used; the frames will be mosaicked.

- Level 3, which includes the East-West and UpDown deformation, obtained by combining, at coarser resolution, the ascending and descending PSI results.
- The EGMS PSI processing will include a baseline processing, which will use the archive imagery, followed by product updates every 12 months.

- The SAR data will be processed at full SLC resolution and using all the available Sentinel-1 acquisitions (currently one repeat pass every 6 days, for all Europe).

- Product reliability is a priority, and as such the production will include appropriate quality control procedures. Such a large-scale production represents an ambitious task.

- A Validation Board will advise and perform independent validation of the EGMS products, maintaining and evolving as necessary the quality standards, and maintaining a frontend information for users on the quality of the EGMS products. The Validation Board may undertake targeted investigations, where the obtained results can be used for improving the EGMS.

- The EGMS will provide tools for visualization, interactive data exploration and analysis, and user uptake elements (protocols and best practice examples) for further ground investigations.

In the context of Copernicus, emphasis will be given to user uptake and the development of new applications based on the EGMS products. A wide gamma of potential users will benefit from the outputs of EGMS. To mention some of them:

- Geological and geophysical surveys;

- Geodetic and topographic surveys;

- Civil Protection authorities;

- Road and railway administrations;

- Water management authorities;

- Cultural heritage institutions;

- Regulators and planners;

- Public authorities at European, national, regional and municipal levels;

- Mining industry;

- Oil and gas industry;

- Engineering companies; 


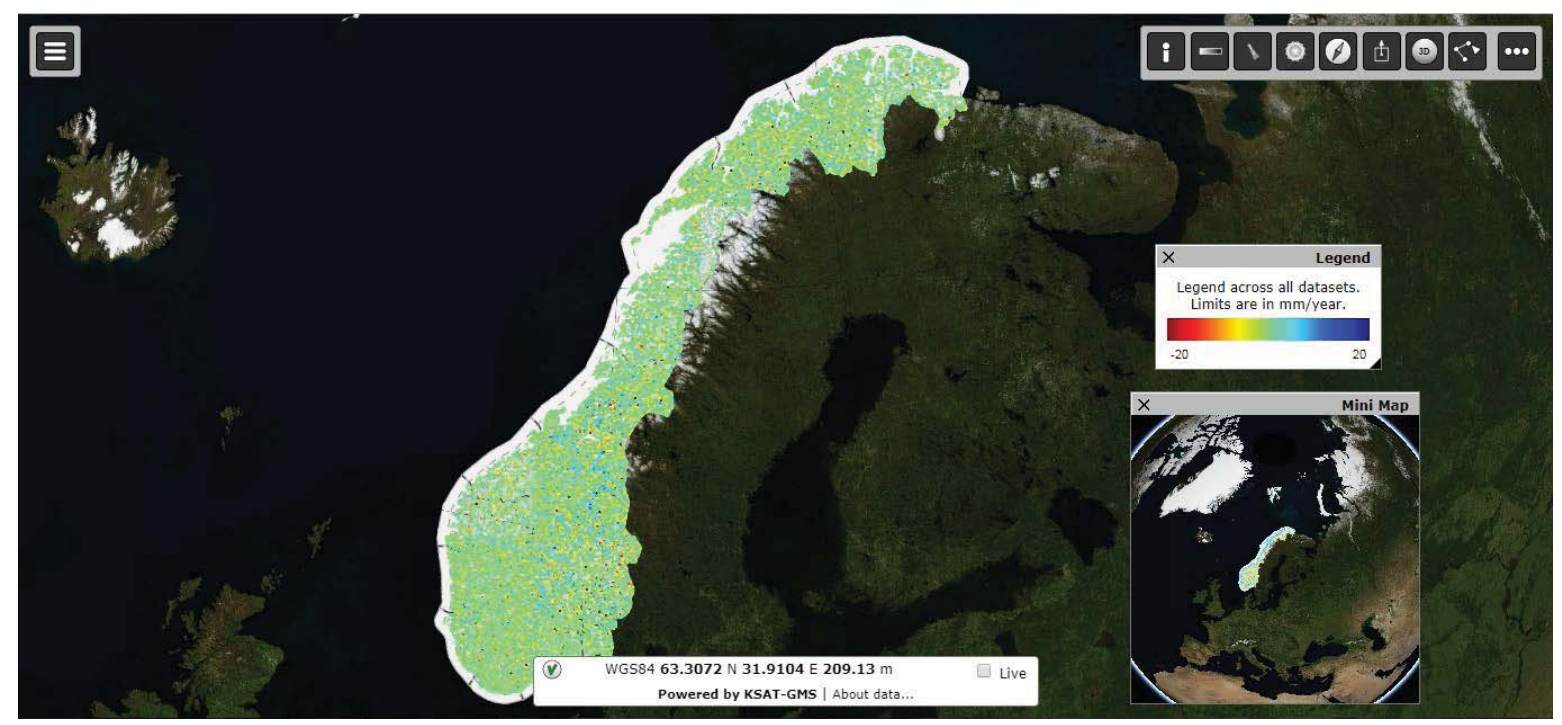

Figure 4: View of the geoportal of Norway - https://insar.ngu.no.

- Insurance industry;

- Research centers and universities;

- Citizens.

It is important to note that the familiarity with the PSI technique and the resulting products may differ per the above listed potential users. And, within a given user category, there are important differences between different European countries. All this will be addressed in the user uptake activities.

\section{ACKNOWLEDGEMENTS}

This work has been partially funded by the Spanish Ministry of Economy and Competitiveness through the DEMOS project "Deformation monitoring using Sentinel-1 data" (Ref: CGL2017-83704-P).

\section{REFERENCES}

Barra, A., Monserrat, O., Mazzanti, P. Esposito, C., Crosetto, M., Scarascia Mugnozza, G., (2015). First insights on the potential of Sentinel- 1 for landslides detection. Geomatics Natural Hazards and Risks. 7(6), 1-10.

Béjar-Pizarro, M., Notti, D., Mateos, R.M., Ezquerro, P., Centolanza, G., Herrera, G., Bru, G., Sanabria, M., Solari, L., Duro, J. and Fernández, J., 2017. Mapping vulnerable urban areas affected by slow-moving landslides using Sentinel-1 InSAR data. Remote Sensing. 9(9), 876.

Carlà, T., Farina, P., Intrieri, E., Ketizmen, H., Casagli, N. (2018). Integration of ground-based radar and satellite InSAR data for the analysis of an unexpected slope failure in an openpit mine. Engineering Geology, 235, 39-52.

Carnec, C., Massonnet, D., King, C., 1996. Two examples of the use of SAR interferometry on displacement fields of small spatial extent. Geophysical Research Letters, 23(24), 35793582 .
Comerci, V., Vittori, E. (2019). The Need for a Standardized Methodology for Quantitative Assessment of Natural and Anthropogenic Land Subsidence: The Agosta (Italy) Gas Field Case. Remote Sensing. 11(10), 1178.

Costantini, M., Ferretti, A., Minati, F., Falco, S., Trillo, F., Colombo, D., Novali, F., Malvarosa, F., Mammone, C., Vecchioli, F. and Rucci, A., 2017. Analysis of surface deformations over the whole Italian territory by interferometric processing of ERS, Envisat and COSMO-SkyMed radar data. Remote Sensing of Environment, 202, 250-275.

Crosetto, M., Monserrat, O., Iglesias, R., Crippa, B., 2010. Persistent Scatterer Interferometry: potential, limits and initial C- and X-band comparison. Photogrammetric Engineering \& Remote Sensing, 76(9), 1061-1069.

Crosetto, M., Monserrat, O., Cuevas-González, M. Devanthéry, N., Crippa, B., 2016. Persistent Scatterer Interferometry: a review. ISPRS Journal of Photogrammetry and Remote Sensing, 115, 78-89.

Dai, K., Li, Z., Tomás, R., Liu, G., Yu, B., Wang, X., Cheng, H., Chen, J. and Stockamp, J., 2016. Monitoring activity at the Daguangbao mega-landslide (China) using Sentinel-1 TOPS time series interferometry. Remote Sensing of Environment. $186,501-513$.

Dalla Via, G., Crosetto, M., Crippa, B., 2012. Resolving vertical and east-west horizontal motion from differential interferometric synthetic aperture radar: The L'Aquila earthquake. Journal of Geophysical Research: Solid Earth (1978-2012), 117(B2).

Del Soldato, M., Solari, L., Raspini, F., Bianchini, S., Ciampalini, A., Montalti, R., Ferretti, A., Pellegrineschi, V., Casagli, N. (2019). Monitoring Ground Instabilities Using SAR Satellite Data: A Practical Approach. ISPRS International Journal of Geo-Information. 8(7), 307. 
De Luca, C., Zinno, I., Manunta, M., Lanari, R., Casu, F., 2017. Large areas surface deformation analysis through a cloud computing P-SBAS approach for massive processing of DInSAR time series. Remote Sensing of Environment. 202, 317.

Devanthéry, N., Crosetto, M., Monserrat, O., Crippa B., Mróz, M. (2018): Data analysis tools for persistent scatterer interferometry based on Sentinel-1 data, European Journal of Remote Sensing, 52(S1), 15-25.

Du, Z., Ge, L., Ng, A. H. M., \& Li, X. (2018a). Investigation on mining subsidence over Appin-West Cliff Colliery using timeseries SAR interferometry. International Journal of Remote Sensing. 39(5), 1528-1547.

Du, Z., Ge, L., Ng, A. H. M., Zhu, Q., Yang, X., \& Li, L. (2018b). Correlating the subsidence pattern and land use in Bandung, Indonesia with both Sentinel-1/2 and ALOS-2 satellite images. International Journal of Applied Earth Observation and Geoinformation. 67, 54-68.

EGMS Task Force (2017), https://land.copernicus.eu/usercorner/technical-library/egms-white-paper.

Ferretti, A., Prati, C., Rocca, F., 2000. Nonlinear subsidence rate estimation using permanent scatterers in differential SAR interferometry. IEEE TGRS. 38(5), 2202-2212.

Ferretti, A., Prati, C., Rocca, F., 2001. Permanent scatterers in SAR interferometry. IEEE TGRS. 39(1), 8-20.

Galloway, D.L., Hudnut, K.W., Ingebritsen, S.E., Phillips, S.P., Peltzer, G., Rogez, F., Rosen, P.A., 1998. Detection of aquifer system compaction and land subsidence using interferometric synthetic aperture radar, Antelope Valley, Mojave Desert, California. Water Resources Research. 34(10), 2573-2585.

Goldstein, R.M., Engelhardt, H., Kamb, B., Frolich, R.M., 1993. Satellite radar interferometry for monitoring ice sheet motion: application to an Antarctic ice stream. Science. 262(5139), 1525-1530.

Hanssen, R., 2001. Radar interferometry. Kluwer Academic Publishers, Dordrecht (The Netherlands).

Intrieri, E., Raspini, F., Fumagalli, A., Lu, P., Del Conte, S., Farina, P., Allievi, J., Ferretti, A., Casagli, N., 2018. The Maoxian landslide as seen from space: detecting precursors of failure with Sentinel-1 data. Landslides. 15(1), 123-133.

Massonnet, D., Rossi, M., Carmona, C., Adragna, F., Peltzer, G., Feigl, K., Rabaute, T., 1993. The displacement field of the Landers earthquake mapped by radar interferometry. Nature. 364(6433), 138-142.

Massonnet, D., Briole, P., Arnaud, A., 1995. Deflation of Mount Etna monitored by spaceborne radar interferometry. Nature, 375, 567-570.

Massonnet, D., Feigl, K.L., 1998. Radar interferometry and its application to changes in the Earth's surface. Reviews of Geophysics. 36(4), 441-500.

Ng, A. H. M., Ge, L., Du, Z., Wang, S., Ma, C. (2017). Satellite radar interferometry for monitoring subsidence induced by longwall mining activity using Radarsat-2, Sentinel-1 and ALOS-2 data. International Journal of Applied Earth Observation and Geoinformation. 61, 92-103.

Novellino, A., Cigna, F., Brahmi, M., Sowter, A., Bateson, L., Marsh, S. (2017). Assessing the feasibility of a national InSAR ground deformation map of Great Britain with Sentinel-1. Geosciences. 7(2), 19.

Raspini, F., Bianchini, S., Ciampalini, A., Del Soldato, M., Solari, L., Novali, F., Del Conte, S., Rucci, A., Ferretti, A. and Casagli, N., 2018. Continuous, semi-automatic monitoring of ground deformation using Sentinel-1 satellites. Scientific reports, 8(1), 7253 .

Showstack, R. (2014). Sentinel satellites initiate new era in earth observation. Eos, Transactions American Geophysical Union. 95(26), 239-240.

Solari, L., Del Soldato, M., Montalti, R., Bianchini, S., Raspini, F., Thuegaz, P., Bertolo, D., Tofani, V. and Casagli, N., 2019. A Sentinel-1 based hot-spot analysis: landslide mapping in north-western Italy. International Journal of Remote Sensing. 40(20), 7898-7921

Sowter, A., Amat, M. B. C., Cigna, F., Marsh, S., Athab, A., Alshammari, L. (2016). Mexico City land subsidence in 20142015 with Sentinel-1 IW TOPS: Results using the Intermittent SBAS (ISBAS) technique. International Journal of Applied Earth Observation and Geoinformation. 52, 230-242.

Torres, R., Snoeij, P., Geudtner, D., Bibby, D., Davidson, M., Attema, E., Potin, P., Rommen, B., Floury, N., Brown, M., Traver, I.N. (2012). GMES Sentinel-1 mission. Remote Sensing of Environment. 120, 9-24.

Vecchiotti, F., Peduto, D., Strozzi, T. (2017). Multi-sensor a priori PSI visibility map for nationwide landslide detection in Austria. In Workshop on World Landslide Forum, 45-52, Springer, Cham.

Zhou, L., Guo, J., Hu, J., Li, J., Xu, Y., Pan, Y., \& Shi, M. (2017). Wuhan surface subsidence analysis in 2015-2016 based on sentinel-1a data by SBAS-InSAR. Remote Sensing. 9(10), 982.

Zinno, I., Mossucca, L., Elefante, S., De Luca, C., Casola, V., Terzo, O., Casu, F., Lanari, R. (2015). Cloud computing for earth surface deformation analysis via spaceborne radar imaging: A case study. IEEE Transactions on Cloud Computing, 4(1), 104-118. 